\title{
TESTING FOR LONG MEMORY IN THE LKR/USD EXCHANGE RATE: EVIDENCE FROM SRI LANKA
}

\author{
Sivarajasingham $S^{*}$, Balamurali.$N^{* *}$ \\ *University of Peradeniya, Sri Lanka ssivarajasingam@gmail, \\ ** Open University Sri Lanka nbala@ou.ac.lk
}

\begin{abstract}
The question of whether exchange rate markets are efficient or not, is directly related to whether or not long memory is present in the exchange rate changes. Therefore, this paper explores the nature of the data generating processes of foreign exchange rate LKR against the US Dollar (USD), (LKR/USD) by examining the long memory properties of the LKR/USD return series based on econophysics models. In this study, autocorrelation function and spectral density function are used as visual test to inspect long memory of exchange rate returns. Further, parametric-ARFIMA model, Semi-parametric test proposed by Geweke and Porter-Hudak, Local Whittle estimator and non-parametric $(R / S)$ test are employed as inferential tests to examine the long memory properties of the LKR/USD using daily data for the period from 2005-01-03 to 2016-12-30. Kernel density of LKR/USD return series show peak and fat tail postures. Visual inspection and inferential results reveal strong evidence of long memory property in the daily LKR/USD exchange rate return. It indicates that pricing by the market participants is not efficient. The results of this study have policy implications for traders and investors in designing and implementing trading strategies. It can also be helpful in predicting expected future return. Thus, the results of this study should be useful to regulators, practitioners and investors.
\end{abstract}

Keywords: ARFIMA, exchange rate, GPH, Local Whittle Estimator, Long Memory, Hurst Exponent .

\subsection{Introduction}

In a globalized world, today, exchange rate plays a prominent role in international trade. The behavior of foreign exchange rates is of great importance to international investors. The nature of exchange rate dynamics is important for traders and investors in foreign currency markets. Understanding of long range dependence (long memory) of exchange rate return dynamics can be helpful in estimating expected return hence in designing, and implementing trading strategies. Hence, the study of the long memory property of exchange rate return is important for market participants. Long memory of exchange rate is a topic that has not received its due attention from academics in Sri Lanka.

The aim of this study is to examine long memory in the LKR/USD exchange rate in two steps. First, we employ traditional unit 
root tests. Second, we apply fractionally integrated ARMA models that are more flexible long memory models and selected some long memory tests.

This article is organized as follows: Section 2 briefly reviews the literature. Section 3 defines thelong memory model. Section 4 describes the data and methodology of the study. Section 5 discusses the empirical results obtained from various econometric techniques. The final section presents the conclusions.

\subsection{Literature Review}

There exist many empirical studies that test for the presence of long memory in the financial and economic time series. For example, Soofi, Wang and Zhang (2006), Kumar and Maheswaran (2015), Alptekin (2006). Granger and Joyeux (1980), Hosking (1981) proposed the autoregressive fractionally integrated moving average (ARFIMA) model to study long memory processes. Mandelbrot (1972) used the R/S analysis to study long memory. Peters (1991) found evidence of long memory for using $\mathrm{R} / \mathrm{S}$ approach to study the long memory of daily exchange rate data of US dollar, Japanese yen, GBPound, Euro, and Singapore dollar.

Cheung (1993) first studied time series properties of five major nominal exchange rates series using ARFIMA model that provides a direct and convenient frame work to study both short and long memory behavior. Cheung found the statistical evidence for long memory using various estimation techniques $(\mathrm{R} / \mathrm{S}, \mathrm{LO} \mathrm{R} / \mathrm{S}$,
GPH,). Corazza and Malliaris (2002) found evidence that exchange rate return follows a fractional Brownian motion (long memory) by using Hurst exponent method.

De Boefand Granato (1997) reviewed that the data are long memory processes but do not have unit roots, especially in the range $0<d<1$. Even though it does not contain a unit root, it does have long memory, whereby shocks to the series persist for at least 12 months.

However, there are no studies inves -tigating the memory properties of Sri Lankan exchange rates using fractional integration technique. So, this study will be a new attempt to study about LKR/USD exchange rate dynamics based on recent econometric time series analysis in Sri Lanka. A comprehensive understanding of time series and statistical properties of LKR/USD exchange rate in Sri Lanka might provide useful implications for the direction of future research and effective exchange rate and monetary, and trade policies. Therefore, this study would contribute significantly to the existing knowledge.

\subsection{Long-Memory Time Series Model}

A covariance stationary time series is said to exhibit long memory if it satisfies the following condition

$$
\begin{gathered}
\sum_{k=-n}^{n}|\rho(k)| \rightarrow \infty \quad \mathbf{8} \quad \mathrm{n} \rightarrow \infty \\
\text { (not finite) }
\end{gathered}
$$


where $\rho(k)$ is the autocorrelation at lag $\mathrm{k}$. This equatio(astates that the sum of the absolute autocorrelation is infinite and non-summable (McLeod \&Hipel, 1978). If the limit value is finite then the process possesses short memory.

\section{0 Methods}

\section{1 data and variables}

Data used in this study are daily exchange rate series of LKR/USD. The sample covers from $3^{\text {rd }}$ January, 2005 to $30^{\text {th }}$ December 2016. The variable used in this study is LKR/USD which is collected from the website of Central Bank of Sri Lanka. Total number of observations is 2896. The daily changes of the exchange rate is measured by the return series which is defined as below

$$
r_{t}=\ln \left(P_{t}\right)-\ln \left(P_{t-1}\right)
$$

$r_{t}$ represents logged returns at day t., Pt represents closing exchange prices at day t. The Hodrick-Prescott (HP) filter is used to extract the trend component of the series.

\subsection{Analytical methods}

This study uses various econometric techniques to get robust results as each estimation techniques may have limits. Exploratory data analysis (EDA) and parametric, semi-parametric and nonparametric estimation procedures are used to identify and estimate memory parameter of LKR/USD exchange rate dynamics. These techniques can uncover the underlying structure of dynamic behavior of the LKR/USD exchange rates.

\subsubsection{Exploratory data analysis}

EDA; line graphs, autocorrelation function, kernel regression line, confidence ellipse, spectral density function are used to find novel and useful information that might otherwise remain unknown.

\subsubsection{Unit root tests}

The Augmented Dickey-Fuller (ADF) test, the Phillips and Perron (PP) test and the Kwiatkowski-Phillips-SchmidtShin (KPSS) test are implemented to understand the stationarity of the series (test for unit root). These tests have low power against fractional integration alternatives.

\subsubsection{The Rescaled Range Statistic}

Among various methods that measure long memory is the best known method, the "range over standard deviation statistic" or $(\mathrm{R} / \mathrm{S})$ to detect long range dependence of a series. It is defined as:

$$
(R / S)_{n}=\frac{1}{S_{n}}\left[\operatorname{Max}_{j \leq k \leq n} \sum_{j=1}^{k}\left(x_{j}-\bar{x}_{n}\right)-\operatorname{Min}_{j \leq k \leq n} \sum_{j=1}^{k}\left(x_{j}-\bar{x}_{n}\right)\right]
$$

where $1 \leq k \leq n$

$R(n)$ is the range of the first $n$ values, and $S(n)$ is their standard deviation. Thy $R / S$ statistic is the range of partial sums of deviations of a time series from its mean, rescaled by its standard deviation. This statistic was introduced by Mandelbrot and Wallis (1969) and Hurst (1951). R/S statistic provides the Hurst exponent 
(H). If $0.5<H<1$, the series indicates persistent behavior/long memory, referred as fractional Brownian motion.. If $0.0<H<0.5$, then the series is called anti-persistent (mean-reverting).

\subsubsection{Geweked Porter-Hudak, “d”}

Geweke\& Porter-Hudak, (1983), (GPH), proposed a more robust estimation method based on spectral analysis, a seminonparametric procedure, to test for long memory in terms of fractionally integrated process. According to the GPH method, given the periodogram $I\left(\omega_{j}\right)$ of variable $y$ one can estimate fractional differencing parameter " $d$ " by using the model of a log periodogramregression: $\mathrm{h} I\left(\omega_{j}\right)=$ const $-d \mathrm{~h}\left(4 \sin ^{2}\left(\frac{\omega_{j}}{2}\right)\right)+$ error $_{2 \pi_{j}}$
$\mathrm{j}=1,2, \ldots \ldots, \mathrm{m}, \quad$ frequency $\omega_{j}=\frac{\omega^{N}}{\text { for } \mathrm{j}=1,2 \ldots . \mathrm{m}}$

The null hypothesis of the GPH(3) $H_{0}: d=0$ "there is no long memory"

\subsubsection{Autoregressive fractional integrated moving average (ARFIMA) model}

Granger and Joyeux (1980) and Hosking (1981) introduced the ARFIMA , parametric approach to test the long memory property in the LKR/USD return.

The ARFIMA(p,d,q) process can be written as :

$$
\Phi(L)(1-L)^{d} y_{t}=\Theta(L) \varepsilon_{t}
$$

where $\varepsilon_{t} \sim \operatorname{iid}\left(0, \sigma^{2}\right), \mathrm{L}$ is the lag operator, $\phi(L), \theta(L)$ ae lag polynomials of finite orders. $(1-L)^{d}$ is the fractional differencing operator defined by

$$
(1-L)^{d}=\sum_{k=0}^{\infty} \frac{\Gamma(k-d) L^{k}}{\Gamma(k+1) \Gamma(-d)}
$$

$\Gamma($.$) is the Gamma function, \mathrm{y}_{\mathrm{t}}$ is both stationary and invertible if the roots $\Phi(L)$ and $\Theta(L)$ are outside the unit circle and $d<|0.5|$. The parameter $d$ is allowed to assume any real value. Long-memory processes are stationary processes whose autocorrelation functions decay more slowly than short-memory processes. The memory property of a process depends on the value of $d$. when $0<d<0.5$, the process indicates a stationary process with a long memory. Hence, the existence of long memory can be determined by testing for the statistical significance of the sample differencing parameter $d$. Hosking (1981) showed that the autocorrelation, $\rho($.$) , of$ an ARFIMA processes is proportional of $k^{2 d-1}$ as $k \rightarrow \infty,\left[\rho(k) \propto k^{2 d-1}\right]$. It implies that the autocorrelations of the ARFIMA processes decay hyperbolically to zero as $k \rightarrow \infty$

\subsection{Empirical Results}

5.1 Basic Features of LKR/USD exchange rate Dynamics in Sri Lanka

The basic features of LKR/USD series are examined by visual inspection using various graphs. Visual inspection indicates that the series seems to be non-stationary. Exchange rate changes defined as return 
series are having high volatility.Mean and variance of the LKR/USD distribution change over time. Variability of return of LKR/USD vary over time and appears in clusters. Figure 1 exhibits a time series plot of LKR/USD and return of LKR/
USD.All price series are moving upward with volatile. Return series appear to be random fluctuations around 0 and with time varying variance.

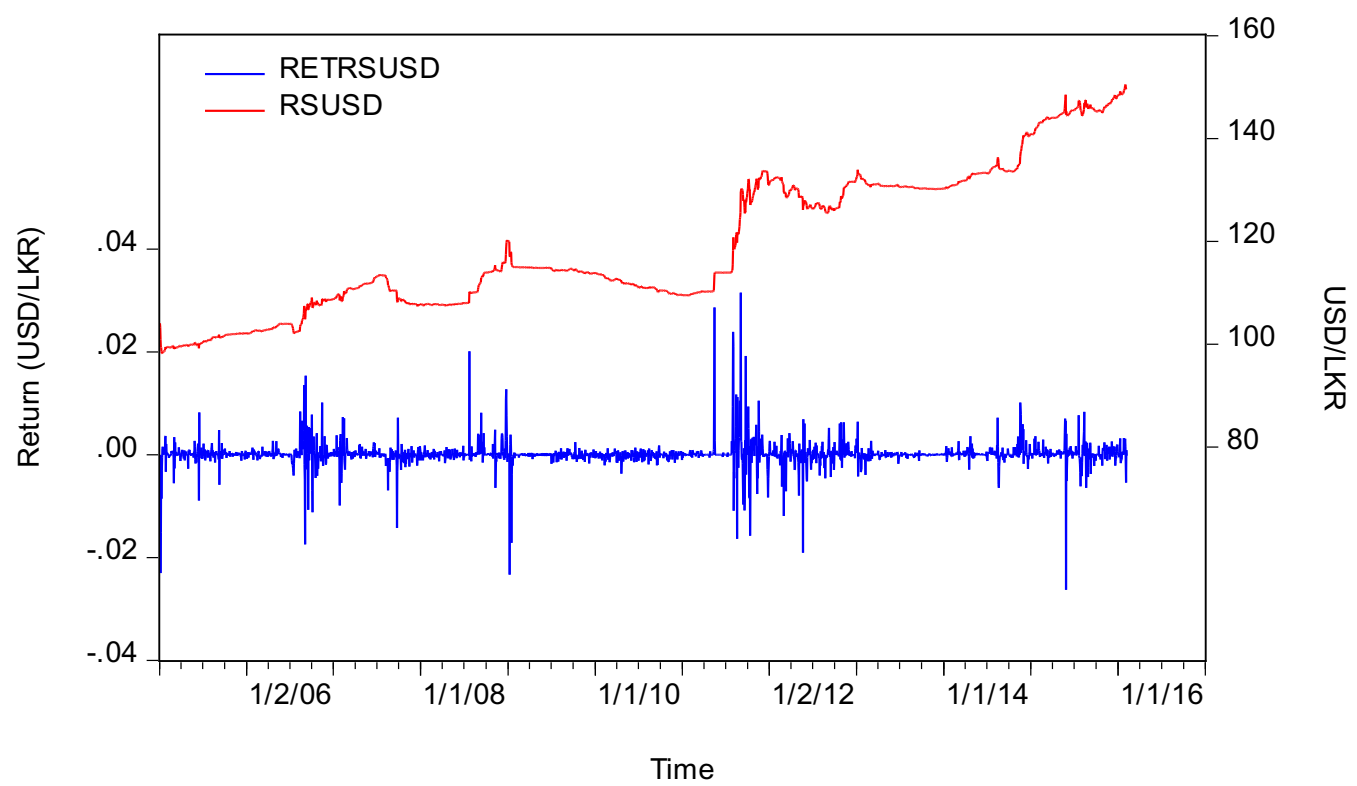

Figure 1 USDLKR and its return behavior, January 3, 2005- December 30, 2016

Return series seem to have 0 mean. But, when we extract the trend using HodrickPrescott (HP) filter, the trend of return is not linear and having little upward movement (Figure 2).

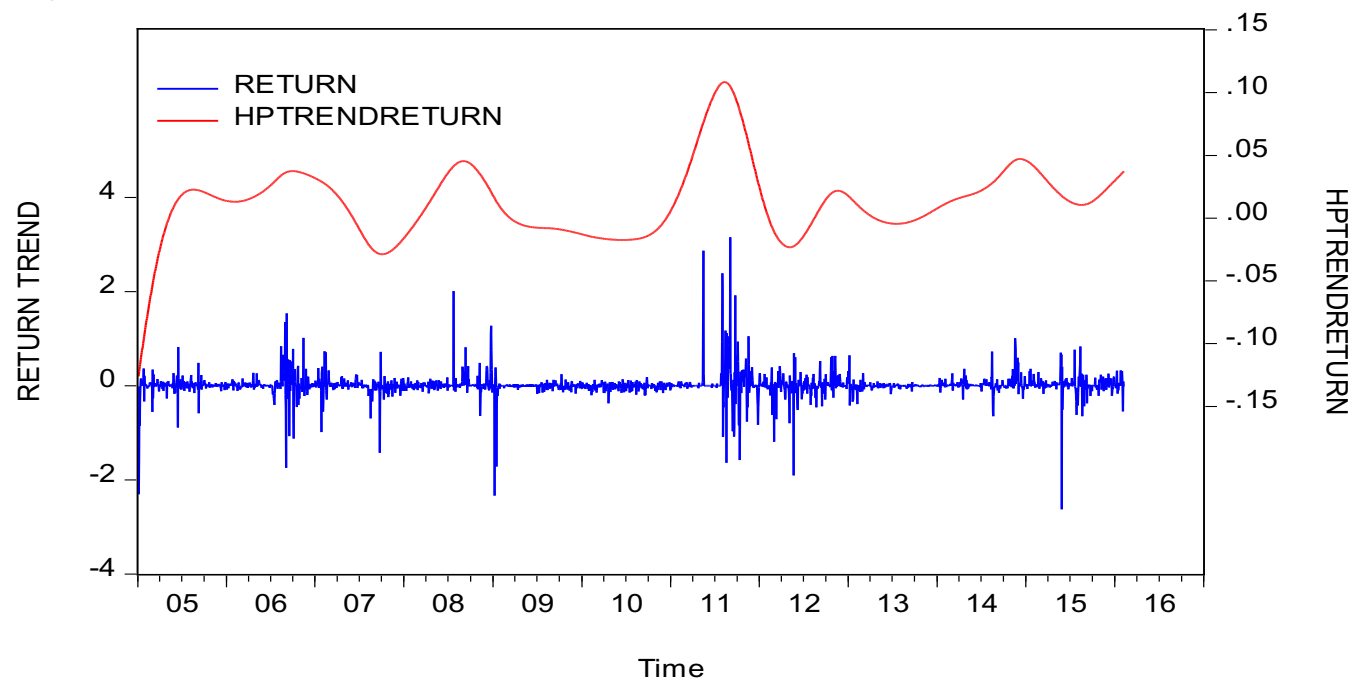

Figure 2 HP trend of return and return of LKR/USD behavior, January 3, 2005December 30, 2016, 
5.2 Empirical behavior of Autocorrelation function structure of LKR/USD, Return

i). Lag Plot - Scatter plot with confidence ellipse

The lagged scatter plot with confidence ellipse, nearest neighbour fit show the dependence nature of the LKR/USD dynamics in level as well as in the rate of

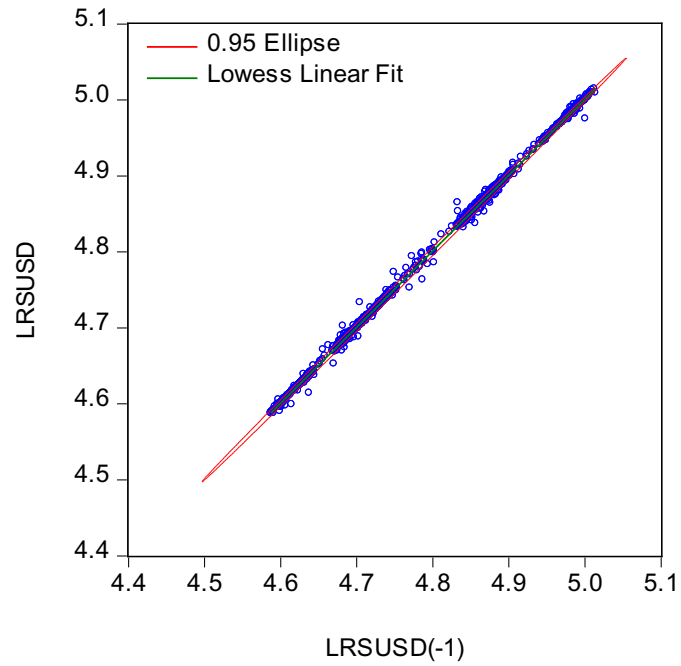

changes.Figure 3 exhibits two lag scatter plots with 95 confidence ellipse one for $\mathrm{LKR} / \mathrm{USD}$ and the other one for HP-trend Return series. These figures suggest that LKR/USD and HP filtered trend return series are positively auto-correlated. Hence, the series is having long range dependence.

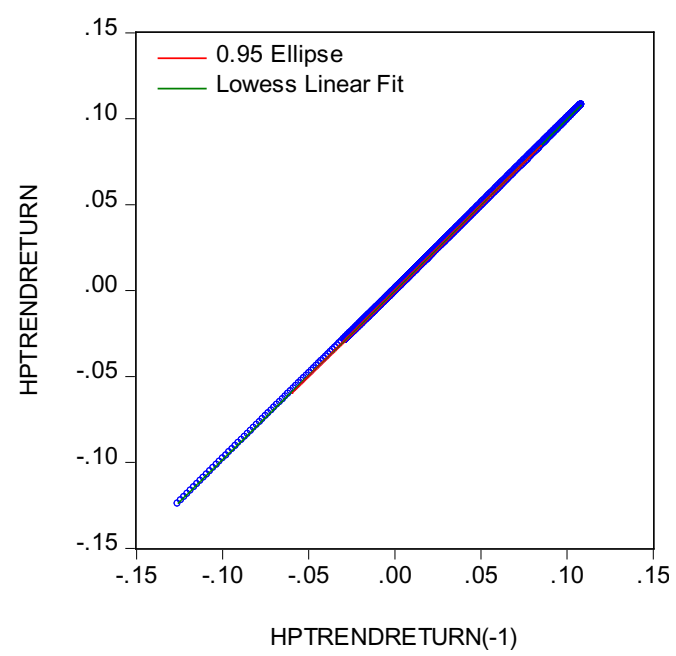

Figure 3 Autocorrelation nature of LKR/USD and its RETURN, January 3, 2005December 30, 2016.

\section{ii) Autocorrelation function for LKR/ USD}

A slow decay of the ACF is an indicator of long memory. Sample ACFs for LKR/USD decay slowly to zero at a polynomial rate as the lag increases. This type of process is referred to as long-memory time series. The autocorrelation coefficient of LKR/USD starts at a very high value (0.999) close to 1 and declines very slowly toward zero as the lag lengthens (Figure 4).
Autocorrelations for the first 50 lags range between approximately 0.999 and 0.924 providing strong evidence of the presence of serial correlation. Results indicate thatLKR/USD series has a very long memory and is largely persistent with lagged coefficients that are clearly statistically significant. The impact of a shock $\varepsilon_{t}$ on LKR/USD does not diminish over time. 


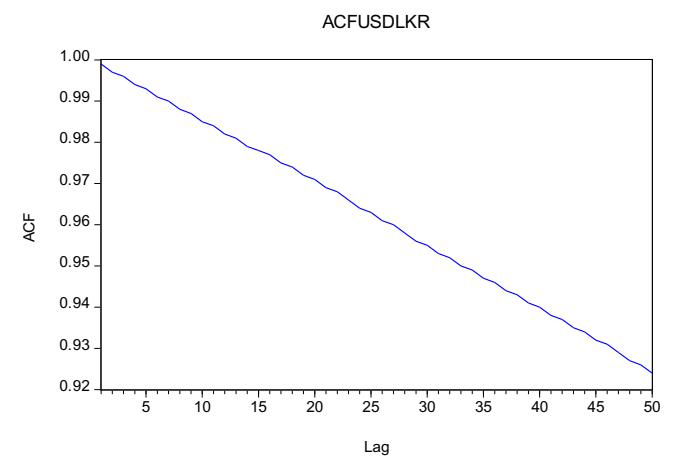

Figure 4 Autocorrelation function of LKR/USD

\section{iii) Autocorrelation function for return of LKR/USD}

Figure 5 shows the ACF of return decays slowly as a function of time lag. However, it seems that it does not explicitly exhibit long memoryat the beginning and not have a smooth behavior. Sample autocorrelations of return of LKR/ USD are statistically significant at a 5 percent level for long lags. In order to overcome this muddle, we employ HP filter and test for long memory.

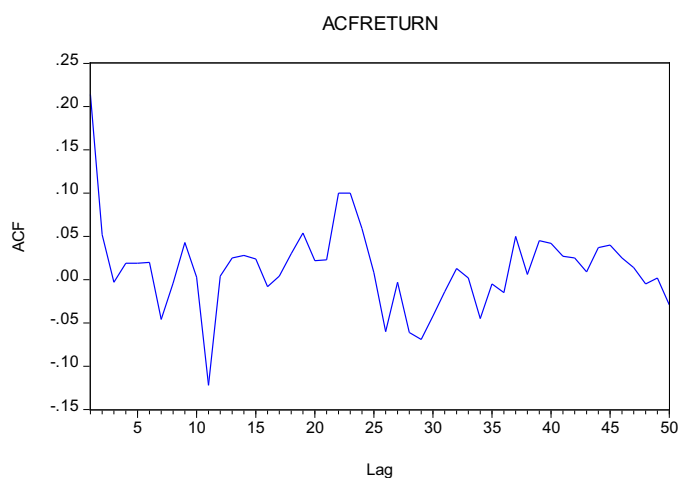

Figure 5Autocorrelation function for return of USD-LKR

Figure 6 shows the ACF of HP filtered return series that shows strong evidence of long memory. ACF decays very slowly with lags.

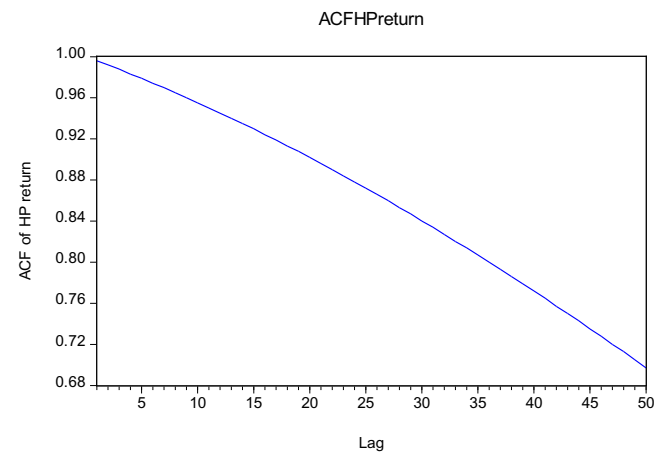

Figure 6 Autocorrelation function for HP filtered trend series of return of LKR/USD

These sample ACFs show that the impact of a shock $\varepsilon_{t}$ on exchange rate series does not diminish over time. The past shocks continue to play a significant role in determining the future exchange rate path.

The $p$ value for (Ljung-Box test statistic) the joint significance of the correlation coefficients, indicates that they are significantly different from zero even for large lags. This implies the autocorrelation exist for longer time.

\subsection{Visual Inspection of Spectral Density Function}

In addition, spectral methods are useful to uncover key characteristics of economic time series for model building. Granger (1966) describes how the spectral shape of an economic variable concentrates spectral mass at low frequencies, declining smoothly as frequencies increases. The series $y_{t}$ displays long memory if its spectral density, $f_{\mathrm{Y}}$ increases without limit as angular frequency tends to zero. $\lim _{\lambda \rightarrow 0} f_{Y}(\lambda)=\infty$. In a spectral graph, spectral 
density is increasing without limit when frequency tends to zero. The SDF is inbounded at zero frequency. This type of characteristics of spectral density function (SDF) indicates that return of LKR/USD has a long memory.

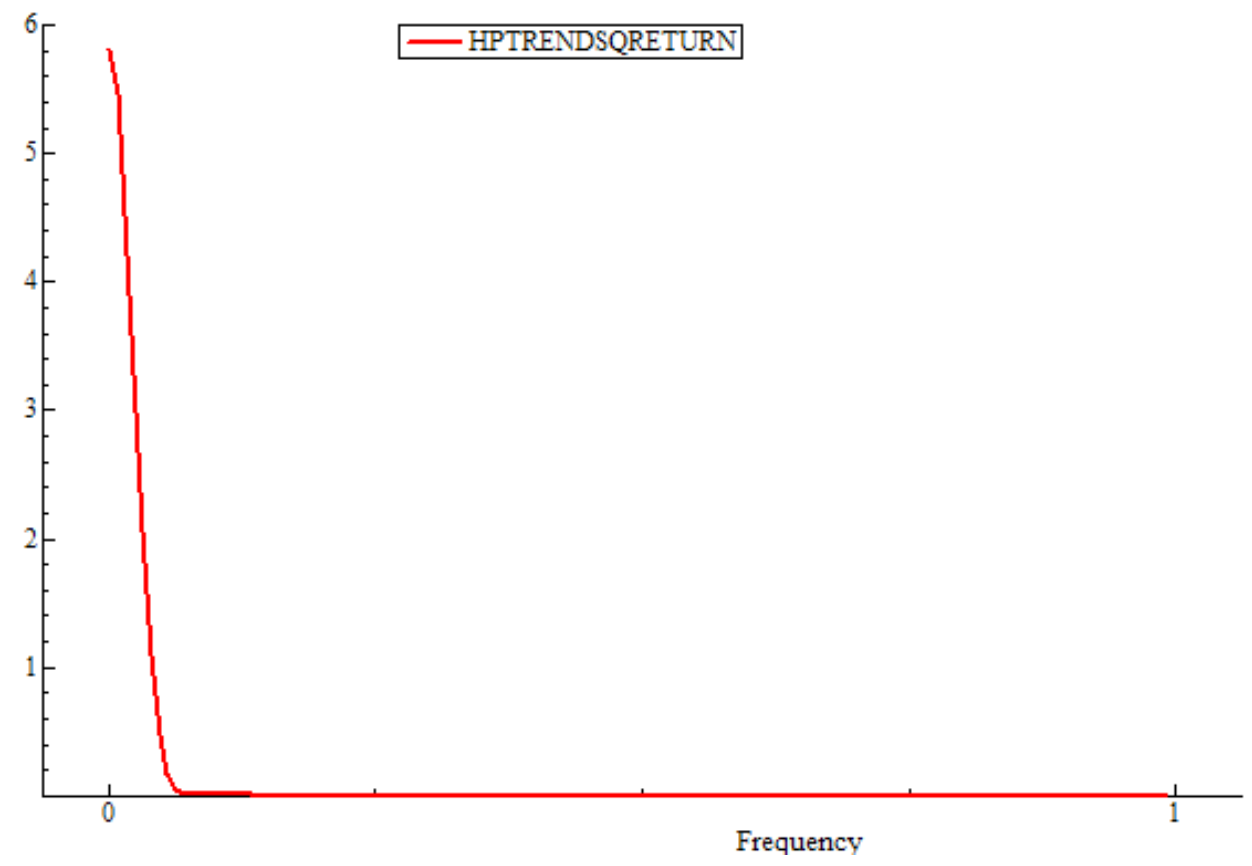

Figure 6 : Spectral Density function for Return of LKR/USD

In order to validate the results of visual inspection, the inferential analysis is further performed using non-parametric, semi-parametric and parametric approaches.

\subsection{Unit root test Results}

The results of standard unit root tests ADF, PP, and KPSS show the LLKR/USD are non-stationary, I(1) and return series (first difference) is stationary, $\mathrm{I}(0)$. All these tests only count the integer order of integration of the series, I(1) or I(0). It has not identified the fractional integration.

Table 4: ADF Unit root test results for level data

\begin{tabular}{|l|l|l|l|l|l|l|}
\hline \multirow{2}{*}{} & \multicolumn{4}{|l|}{$\begin{array}{l}\text { Level with intercept } \\
\text { and trend }\end{array}$} & \multicolumn{2}{l|}{$\begin{array}{l}\text { First difference with } \\
\text { intercept }\end{array}$} \\
\cline { 2 - 7 } & \multicolumn{4}{|l|}{ Test Statistics } & \multicolumn{2}{l|}{ Test Statistics } \\
\cline { 2 - 6 } & ADF & PP & KPSS & ADF & PP & KPSS \\
\hline Series & -2.086 & -2.139 & 0.494 & -43.364 & 43.278 & 0.176 \\
& $(0.553)$ & $(0.523)$ & {$[0.146]$} & $(0.000)$ & $(0.000)$ & {$[0.463]$} \\
\hline
\end{tabular}

Probability values are in ( ). Critical values are [ ] 
However, fractional integration can be analyzed by R/S, GPH, ARFIMA model, FIGARCH model.

\subsection{The Rescaled Range Statistic-Hurst Estimator (H)}

The results of the rescaled range analysis (Table 5) show that Hestimates for Log LKR/USD, HP filtered trend for Log LKR/USDare greater than 0.5. It implies that Log LKR/USD and HP filtered seriesexhibit long memory. It implies strong evidence for long memory in LKR/USD series $(0.5<H<1)$.

In the case of return series, It has not shown any evidence of long memory due to noise. Hence, the noise is separated from the trend. HP filtered trend series werederived from return series to estimate memory parameter. R/S estimate for HP filtered series is 0.87 with probability 0.000 .

Table-5: Hurst-Mandelbrot R/S Estimates

\begin{tabular}{|l|c|c|}
\hline & \multicolumn{2}{|c|}{$R / S$ - Hurst Exponent estimates } \\
\hline Price Series & $H$ & $H^{l}$ \\
\hline Log LKR/USD & 1.02 & 0.997 \\
Standard error & $(0.011)$ & {$[0.008)$} \\
P value & {$[0.000]$} \\
\hline Return LKR/ & Not signifi- & \\
USD cant & 0.874 \\
Standard error & & $(0.041)$ \\
(SE) & & {$[0.000]$} \\
P value & & \\
\hline
\end{tabular}

Note: SE are in ( ), p values are in [ $]^{1}$ :denotes Hodrick-Prescott filtered trend,

$0<H<0.5$ :Anti-persistent, $H=0.5$ :Random walk, $0.5<H<1$ :Long memory
It is interesting to note that LKR/USD return series does not have significant long memory estimates. However, HP filtered trend of return series shows the evidence of long memory.

5.6 Semi-Parametric GPH Estimate " $\hat{d}$ "

We compute the fractional integration parameter using algorithms built in GRETL. There are two methods we use here to estimate fractional parameter " $d$ " (i) proposed by Geweke and Porter-Hudak $\operatorname{method}\left(d_{\mathrm{GPH}}\right)$ (ii) Local Whittle estimator $\left(d_{\mathrm{LW}}\right)$ : both of these methods estimate " $d$ " using a frequency domain maximum likelihood estimation. The results are given in Table 6.

Table 6: Geweke and Porter-Hudak Estimates and Local Whittle Estimates

\begin{tabular}{|l|c|c|}
\hline Series & GPH" $\hat{d}^{\prime \prime}$ & LWE “ $\hat{d}$ " \\
\hline LLKRUSD & 0.989 & 1.000 \\
& $(0.000)$ & $(0.000)$ \\
\hline Return of & 0.129 & 0.130 \\
LLKRUSD & $(0.048)$ & $(0.005)$ \\
\hline $\begin{array}{l}\text { HP trend of re- } \\
\text { turn }\end{array}$ & 0.91 & 1.05 \\
& $(0.000)$ & $(0.000)$ \\
\hline
\end{tabular}

Note: SE are in ( ), P values are in parenthesis

GPH " $d$ " estimates (Table 6) show the LKR/USD is fractionally integrated and has long memory. As the estimated " $d$ " values close to one $(\sim 1)$ for LKR/USD series. Though estimated values of GPH and LWE destimates for return of LKR/ USD series is statistically significant at the 5 percent level and less than 0.5 , the HP filtered trend of the return series has GPH 
$\mathrm{d}=0.91$, LWE $\mathrm{d}=1.05$. This indicatethat the return of LKR/USD has long memory.

\subsection{ARFIMA Model}

ARFIMA model is used to estimate long memory parameter using maximum likelihood estimation method. Table 7 shows Long memory parameter estimates for the selected ARFIMA models for the return series.

Table 7: Results from ARFIMA $(\mathrm{p}, \mathrm{d}, 0)$ Models for Log LKR/USD and

Return series.

\begin{tabular}{|l|c|c|c|c|c|}
\hline Items & $\begin{array}{c}\text { Con- } \\
\text { stant }\end{array}$ & AR & $\boldsymbol{d}$ & LL & $\begin{array}{c}\text { Wald- } \\
\mathrm{Chi}^{2}\end{array}$ \\
\hline Return & & & & & \\
of LKRUSD & $\begin{array}{c}0.013 \\
(0.299)\end{array}$ & $\begin{array}{c}0.144 \\
(0.000)\end{array}$ & $\begin{array}{c}\mathbf{0 . 1 4 4} \\
(0.000)\end{array}$ & 235.59 & 69.26 \\
\hline
\end{tabular}

Note: This table shows the results of selected ARFIMA( $p, d, 0)$ models. AR indicates the autoregressive parameter, LL indicates the log likelihood, $\mathrm{p}$ values are in parentheses, $\mathrm{d}=$ fractional difference parameter, ( $\mathrm{P}$ values are in parenthesis $\mathrm{H} 0: \mathrm{d}=0$ )
In return-LKR/USDcases, estimates of long memory parameter $d$ and AR parameters which are highly statistically significant at the 5 percent level. LM parameter estimates lie in the interval $(0$, $0.5)$, implying that the series exhibit long memory. Long memory indicates that shocks to LKR/USD may persist over a long period of time. These evidences imply predictability of future LKR/USD based on historical prices.

The impulse response function (IRF) (Campbell and Mankiw, 1987, Watson 1986) of estimated ARFIMA model is one measure of the LM in exchange rate changes. The IRF measures the effect of a unit shock on the k-period-ahead exchange rate change. The estimated IRF shows (Figure 7) a positive shock to LKR/ USD return and has an immediate positive impact on LKR/USD with the impacts disappearing at a very hyperbolic rate after first step, for longer time lag period. The magnitude of the response is positive for longer periods.

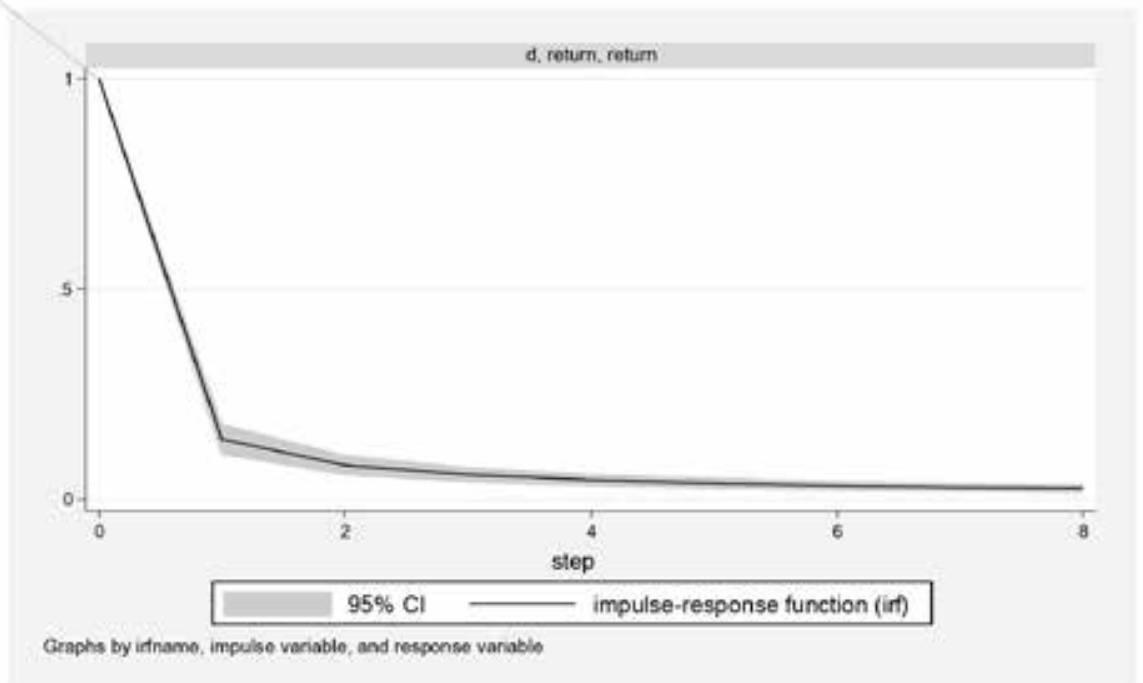

Figure 7 Impulse Response Function of ARFIMA model 


\section{0 Conclusions and Recommendations}

In this study, we estimated fractional difference parameter (LM) for exchange rate changes of LKR/USD in Sri Lanka using fractional integration methods. A battery of nonparametric, semiparametric and parametric tests were used to investigate long memory for LKR/USD return series. All these tests show that return series have long memory and they are fractionally integrated. Our results provide support for the hypothesis of longrange dependence in Sri Lankan exchange rates relative to the US dollar. Further, our results are evident against unit root but for long memory. It is noted that the fractional difference parameters are significantly different from 1 as well as from 0 . The persistent behavior of LKR/USD leads to market inefficiency. Further, the findings of this study have policy implications for traders and foreign investors in designing and implementing trading strategies. It can also be helpful in predicting expected future return and volatility. Thus, the results of this study should be useful to regulators, practitioners and investors. Central bank interventions are thought to play an important role in explaining the dynamics of exchange rates. However, Central bank interventions and long memory in exchange rate dynamics are not considered in the study. Therefore, future empirical work in this area should attempt to investigate the Central bank interventions and long memory in exchange rate dynamics.

\section{Acknowledgements:}

Firstauthorwishes to express his gratitude to Prof. dr. Jan G. De Gooijer, University of Amsterdam, The Netherlands. We gratefully acknowledge helpful comments from two anonymous referees.

\section{References}

1. Alptekin, N. (2006). Long memory analysis of USD/TRL exchange rate. International Journal of Social Sciences, 1(2), 111-116.

2. Baillie, R. T. (1996). Long memory processes and fractional integration in econometrics. Journal of Econometrics, 73(1), 5-59.

3. Baillie, R. T., Bollerslev, T., and Mikkelsen, H. O. (1996). Fractionally integrated generalized autoregressive conditional heteroskedasticity. Journal of Econometrics, 74(1), 3-30.

4. Campbell, J. Y., \& Mankiw, N. G. (1987). Are output fluctuations transitory?. The Quarterly Journal of Economics, 102(4), 857-880.

5. Cheung, Y. W., (1993). Long memory in foreign exchange rates, Journal of Business \& Economic Statistics, 11(1), 93-101.

6. Corazza, M. and Malliaris, A.G. (2002). "Multifractality in Foreign Currency Markets," Multinational Finance Journal, 6, 387-401

7. DeBoef, S., \& Granato, J. (1997). Near-integrated data and the analysis of political relationships. American Journal of Political Science, 619-640. 
8. Geweke, J., and Porter-Hudak, S. (1983). The estimation and application of long memory time series models. Journal of time series analysis, 4(4), 221-238.

9. Granger, C. W., and Joyeux, R. (1980). An introduction to long-memory time series models and fractional differencing. Journal of time series analysis, 1(1), 15-29.

10. Hosking, J. R. M. (1981). Fractional differencing. Biometrika 68(1), 165-176.

11. Hsieh, D. A. (1988). The statistical properties of daily foreign exchange rates: 19741983. Journal of international economics, 24(1), 129-145.

12. Hurst, H. E. (1951). Long-term storage capacity of reservoirs. Trans. Amer. Soc. Civil Eng., 116, 770-808.

13. Kumar, D., \& Maheswaran, S. (2015). Long memory in Indian exchange rates: an application of power-law scaling analysis. Macroeconomics and Finance in Emerging Market Economies, 8(1-2), 90-107.

14. Mandelbrot, B. (1972). Statistical methodology for nonperiodic cycles: from the covariance to R/S analysis. In Annals of Economic and Social Measurement, 1(3), 259290. NBER.

15. McLeod, A. I., \& Hipel, K. W. (1978). Preservation of the rescaled adjusted range: 1. A reassessment of the Hurst Phenomenon. Water Resources Research, 14(3), 491-508.

16. Peters, E. E. (1994). Fractal market analysis: applying chaos theory to investment and economics (Vol. 24). John Wiley \& Sons.

17. Soofi, A. S., Wang, S., \& Zhang, Y. (2006). Testing for long memory in the Asian foreign exchange rates. Journal of Systems Science and Complexity, 19(2), 182-190.

18. Watson, M. W. (1986). Univariate detrending methods with stochastic trends. Journal of monetary economics, 18(1), 49-75. 